\title{
Materialidade da norma jurídica tributária da taxa decorrente do exercício do poder polícia: necessidade de efetiva atuação estatal ${ }^{1}$
}

\author{
Sara Dinardi Machado ${ }^{2}$ \\ Thiago Vieira Mathias de Oliveira ${ }^{3}$
}

\section{Resumo}

\begin{abstract}
Analisa o fenômeno da tributação diante dos princípios constitucionais que informam o Estado brasileiro. Relata a definição da Constituição Federal das espécies tributárias e seus respectivos regimes jurídicos, expondo as divergências doutrinárias sobre a mesma. Esclarece que não se pode confundir a classificação dos tributos com a necessidade de vinculação das receitas tributárias. Esmiúça o critério material da hipótese de incidência da taxa de polícia Analisa a significação do termo polícia, apontando as diferenças entre o poder de polícia em sentido amplo e em sentido estrito. Acentua a divergência doutrinária acerca da necessidade de efetiva atuação estatal para caracterização do critério material da hipótese tributária da taxa de polícia. Aponta como conclusões a necessidade de efetiva atuação estatal para dar ensejo à cobrança da taxa de polícia e a necessidade de que essa caracterização seja realizada com fundamento no princípio da legalidade.
\end{abstract}

Palavras-Chave: Taxa; Poder de polícia; Regra matriz de incidência fiscal; Hipótese tributária; Critério material.

\section{Introdução}

O Estado, enquanto instrumento para a satisfação das necessidades sociais, necessita de recursos para realizar esse seu fim, ou seja, precisa de receitas. Por meio do fenômeno da tributação, além de outras meios de menor expressão, o Estado é custeado por seus próprios cidadãos, compelidos a pagar diante da ocorrência de determinados eventos previstos em norma jurídica.

O fenômeno da tributação é melhor entendido quando exposto por meio da teoria da regra matriz de incidência fiscal que sugere um arquétipo para norma jurídica tributária,

1 Este ensaio teve por referência trabalho acadêmico apresentado à disciplina de Direito Tributário da graduação em Direito, de responsabilidade da professora Dra. Marlene Kempfer Bassoli. Agradece-se, aqui, a colaboração daqueles que também contribuíram com a pesquisa: Carlos Alexandre, Edgar, Jorge e Roberto

2 Acadêmica do 5o ano de Direito da Universidade Estadual de Londrina.

3 Acadêmico do 5o ano de Direito da Universidade Estadual de Londrina. 
decompondo-a em elementos (critérios essenciais), constitutivos de qualquer tributo e aptos a determinar o regime jurídico de cada qual, de acordo com seus caracteres essenciais.

Dentre os critérios da regra matriz de incidência fiscal está a hipótese tributária. Trata-se da descrição legal, abstrata e geral, de determinado fato que, uma vez realizado no plano fático, deflagrará uma relação jurídica tributária e dando origem a suas respectivas obrigações. A caracterização deste critério é ponto de enorme divergência doutrinária com relação a uma das espécies tributárias, a taxa de polícia.

A taxa de polícia é tributo cuja exigência depende do exercício do poder de polícia pelo Estado, sendo esse o critério material de sua hipótese tributária. A doutrina concentra sua discussão acerca da necessidade de efetiva atuação estatal para a caracterização do critério material, ou se seria possível a mera potencialidade de tal exercício, podendo, o Estado, apenas disponibilizar seu aparato e, desde já, se inserir como sujeito ativo numa relação jurídica tributária, sendo-Ihe possível a cobrança do tributo.

Para a solução desse conflito doutrinário, não basta a análise superficial das questões, mas sim de cunho constitucional e principiológico da cobrança do tributo, com base na teoria da regra matriz de incidência fiscal, nos termos que se passa a expor.

\section{Estado brasileiro e a tributação por meio das taxas}

O Estado brasileiro optou pela forma republicana de governo que dentre as características principais privilegia a soberania popular, a noção do "público" e a representatividade popular exercida por meio de eleições legítimas e democráticas, do voto secreto e universal. A salvaguarda destes institutos revela a intenção de positivar o valor igualdade no Estado brasileiro. Transpondo esse contexto à matéria tributária, quando da tributação, a idéia de república também deve predominar para que contra o povo não se cometa injustiças ou arbitrariedades. As competências tributárias ${ }^{4}$ da qual o povo é detentor originário não devem ser exercidas em benefício único do poder público e a república brasileira reconhece a todos o direito de somente ser tributado em função do superior interesse do Estado.

\footnotetext{
Competência tributária é o direito subjetivo que cada ente da Federação tem para produzir norma de conteúdo tributário de açor com as hipóteses exclusivamente previstas na Constituição Federal, descrevendo os elementos da norma jurídica tributária.
} 
Neste mesmo contexto, o tratamento isonômico quanto ao dever de pagar tributos (isonomia tributária) e o exercício da competência tributária são previstos constitucionalmente, com a indicação dos critérios que permitem definir o dever de pagar tributos. Dessa forma dispõe o Art. 145 da Constituição Federal:

Art. 145, CF. A União, os Estados, o Distrito Federal e os Municípios poderão instituir os seguintes tributos:

I - impostos;

II - taxas em razão do exercício do poder de polícia ou pela utilização, efetiva ou potencial, de serviços públicos específicos e divisíveis, prestados aos contribuintes ou postos a sua disposição;

III - contribuição de melhoria, decorrente de obras públicas. $[\ldots]$

Pela análise deste dispositivo constitucional e mesmo dos demais dispositivos do que compõem o sistema constitucional tributário, percebe-se que a Constituição Federal não criou tributos, apenas discriminou competências para que os entes federados, por meio de lei, venham a fazê-lo, exercendo cada qual sua competência tributária. A obrigação tributária (obrigação de pagar tributos) só surgirá in abstrato quando construída a norma jurídica tributária e in concreto quando acontecer no mundo fático fato que autorize a cobrança do tributo.

Ainda pela análise da Constituição como um todo e do sistema jurídico brasileiro, contata-se que o Estado brasileiro objetiva, além da igualdade formal (igualdade perante a lei), a realização da igualdade material em que a mesma é buscada, respeitando-se as diferenças entre os indivíduos. Neste embasamento situa-se a mensagem do Art. 145, CF, por meio do qual se identificam as espécies tributárias e os princípios que delineiam o regime jurídico de cada uma delas: impostos (capacidade contributiva), taxas (retributividade) e contribuição de melhoria (obra pública).

Há outros autores, como Luciano Amaro e Hugo de Brito Machado, que acrescentam as contribuições e o empréstimo compulsório como espécies autônomas de tributos. Prefere a classificação de Geraldo Ataliba que, baseado nos sistemas adotados pelo Direito positivo, também agrupa as espécies imposto, taxa e contribuição de melhoria nos sub-grupos:

a) tributos não vinculados (impostos) em que não há contraprestação imediata referida ao Estado frente ao pagamento desses tributos que servem para custear serviços 
gerais. Tem como hipótese de incidência um fato qualquer da esfera do particular que nenhuma relação guarda com a atuação do poder público, embora sempre se relacione, de fato, com o obrigado. A hipótese de incidência dos impostos é uma situação de fato que se constitui em objeto da imposição enquanto considerada manifestação direta ou indireta de certa capacidade contributiva (ATALIBA, 1970, p. 479). Assim, quem paga impostos o faz não em razão do que recebem do Estado, mas de suas potencialidades econômicas;

b) tributos não vinculados (taxas e contribuições de melhoria): há contraprestação específica do Estado para com o cidadão de quem é exigido o tributo, sendo necessário que o Estado faça algo para exigir o tributo do contribuinte. Tem como hipótese de incidência uma atuação estatal diretamente referida ao contribuinte (taxa) ou uma atuação estatal que somente indiretamente atinge o contribuinte, repercutindo na esfera jurídica do mesmo e repousando numa conveniência do poder público ou numa conseqüência qualquer da atuação (contribuição de melhoria). No caso da taxa, a retribuição se perfaz numa atuação estatal que pode ser um serviço público específico e divisível ou o exercício do poder de polícia, também especificamente dirigido ao contribuinte.

O caráter contraprestativo da taxa não significa que para a sua cobrança deva caracterizar uma vantagem específica ao administrado, o que não exclui a necessidade de haver uma correlação entre o valor da taxa e o custo da atividade estatal desempenhada. Aí está o privilégio do princípio da igualdade: os membros da comunidade não podem suportar o ônus de uma atuação estatal dirigida especificamente a um indivíduo, que é quem deve arcar por uma despesa específica que provoca.

O autor classifica os tributos por meio das características de suas respectivas hipóteses de incidência, sendo possível reconhecer-lhes os gêneros e, posteriormente, as espécies (ATALIBA, 1969, p. 43). Sabe-se que a obrigação tributária nasce com a concreta ocorrência de um fato jurídico (evento tributário) a que a lei confere a força jurídica que o torna apto a fazer nascer in concreto cada obrigação. Conforme certas peculiaridades deste fato, hipoteticamente descrito em lei, a obrigação dele nascido será de tributo vinculado ou não. Assim, caso a hipótese de incidência seja uma atuação estatal, estar-se-á diante de um tributo vinculado, se, ao contrário for uma qualidade ou característica da coisa ou pessoa tributada, independente de qualquer atuação estatal, estar-se-á diante de um tributo não vinculado: 
Pois, o legislador sempre erigirá em hipótese de incidência (a) uma atuação qualquer do poder público - ou um efeito desta, ou uma relação fática qualquer desta com o obrigado - ou (b) um outro fato qualquer, que nenhuma relação guarda com a atuação do poder público (embora sempre se relacione, de fato, com o obrigado) (ATALIBA, 1969, p. 45).

O que aqui se expõe não pode ser confundido com a vinculação de receitas que somente são exigidas se previstas constitucionalmente. A vinculação de receitas não é um instituto jurídico, mas um instituto afeto à ciência das finanças. Eis o conceito legal de tributo:

Art. 3ํ, CTN. Tributo é toda prestação pecuniária compulsória, em moeda ou cujo valor nela se possa exprimir, que não constitua sanção de ato ilícito, instituída em lei e cobrada mediante atividade administrativa plenamente vinculada.

Neste mesmo sentido mantém-se a definição da doutrina:

[...] Neste sentido derradeiro, quer exprimir toda da fenomenologia da incidência, desde a norma instituidora, passando pelo evento concreto, nela descrito, até o liame obrigacional que surge à luz com a ocorrência daquele fato (CARVALHO, 2004, p. 23-4).

[...] o jurista conceitua o tributo como sendo uma obrigação jurídica ex lege, tendo como sujeito ativo uma pessoa pública e sujeito passivo uma pessoa subordinada a seu poder, tendo por objeto a transferência de uma soma em dinheiro (ATALIBA, 1970, p. 478).

Por essas definições legais e doutrinárias do tributo, observa-se que os motivos e finalidades da criação, a destinação do dinheiro, a eventual discordância do sujeito passivo, etc., são absolutamente estranhas ao seu conceito jurídico. A destinação da receita de tributos é matéria de direito financeiro, que se dedica a estudar como o resultado da sua arrecadação pode ser apto a manter as atividades públicas que correspondam aos seus fatos geradores, e não tributário.

\section{A caracterização da taxa no sistema jurídico brasileiro}

O tratamento que o ordenamento jurídico brasileiro dá à taxa, que se inicia em nível constitucional, é abundante, estrito e minucioso, o que submete a lei ordinária a um regime severo. "Desde que nossas constituições traçam limitações à taxa, completadas pelas normas gerais de direito tributário, a legislação ordinária não pode, evidentemente, ter a mesma esfera de liberdade que tem alhures" (ATALIBA, 1970, p. 476). A Constituição 
Federal, ao acatar a classificação doutrinária das espécies tributárias (impostos, taxas e contribuições de melhoria), deu-lhe status de princípio constitucional e, como tal, imodificáveis ou insuperáveis pela legislação ordinária.

A taxa é a espécie tributária que se constitui numa obrigação cuja hipótese tributária é uma atividade estatal atual ou potencial, relacionada de modo específico ao contribuinte. Dependendo da natureza da atuação estatal, diferenciam-se as duas espécies de taxas previstas no sistema tributário brasileiro:

- prestação de serviço público específico e divisível: dá ensejo à cobrança de taxa de serviço;

- exercício do poder de polícia: dá ensejo à cobrança de taxa de polícia.

\subsection{Regra matriz das taxas decorrentes do exercício do poder de polícia}

\subsubsection{Hipótese Tributária (de incidência)}

Não cabe neste momento analisar todos os segmentos da norma jurídica tributária, mas apenas traçar um panorama acerca da problemática que circunda a hipótese tributária da taxa de polícia, em especial quanto a seu critério material.

O critério material da taxa de polícia é a atividade estatal de polícia prestada diretamente ao contribuinte.

Esmiuçando o conceito apresentado, tem-se que:

polícia é expressão que designa a intervenção reguladora da administração pública - obviamente imposta ou consentida em lei - restringindo ou limitando a liberdade e a propriedade privada, para tornar possível, dentro da ordem, o concorrente exercício de todas as atividades e a conservação perfeita de todas as propriedades privadas (BARBOSA apud ATALIBA, 1969, p. 47).

Ainda acrescenta Laurence $H$. Tribe que "foi a jurisprudência americana a responsável pela expansão do seu campo de abrangência, entendendo a expressão não como restrita à manutenção da ordem pública e da segurança, mas como envolvente de todas as esferas relacionadas ao interesse público" (TRIBE apud PAULSEN, 2002, p. 568). E ainda, de acordo com Celso Antônio Bandeira de Mello (2004, p.733), 
pode-se definir a polícia administrativa como a atividade da Administração Pública, expressa em atos normativos ou concretos, de condicionar, com fundamento em sua supremacia geral e na forma da lei, a liberdade e a propriedade dos indivíduos, mediante ação ora fiscalizadora, ora preventiva, ora repressiva, impondo coercitivamente aos particulares um dever de abstenção ('non facere') a fim de conformar-Ihes os comportamentos aos interesses sociais consagrados no sistema normativo.

Poder de polícia é a faculdade que o Estado tem de, dentro dos limites constitucionais de competência de cada ente federado (exercício regular do poder de polícia), baixar regras de nível legal ou infralegal, para disciplinar o exercício dos direitos à liberdade e à propriedade das pessoas, protegendo as pessoas no que se refere à sua integridade física e moral, à sua saúde, à higiene, aos costumes, à tranqüilidade pública, aos bens de sua propriedade, à propriedade pública e ao comportamento humano, compatibilizando-os com o bem comum.

A rigor, segundo autorizados doutrinadores, poder de polícia não é atividade da Administração. É o poder do Estado. Deve ser exercido mediante produção legislativa. A Administração Pública, com fundamento nesse poder, e dentro dos limites impostos pelo ordenamento jurídico, exerce atividade de polícia. O que o CTN (Código Tributário Nacional) define como poder de polícia, no dispositivo supracitado, na verdade é atividade de polícia. Prevaleceu, no Código, a terminologia mais difundida (grifos do autor) (MACHADO, 2004, p. 402).

Em sentido amplo, o poder de polícia pode ser entendido como: a) disciplinamento do uso da propriedade (uso, gozo, disposição), já que a propriedade privada não é plena; b) restrições ao exercício da liberdade individual, que também não é plena.

A Constituição Federal e as leis ordinárias atribuem o dever de fiscalização de cada ente da Federação. Em regra, a União fiscaliza o cumprimento das leis federais, os estados, leis estaduais e os municípios de leis municipais. Este disciplinamento geralmente se dá por meio da edição, pelo Poder Legislativo de leis que, na maioria das vezes, exigem do Poder Executivo sua regulamentação por meio da edição de atos administrativos (leis de caráter administrativo - Portarias, Decretos etc.) e posteriormente lei que preveja a cobrança de taxas em decorrência da atividade de fiscalização (leis de caráter tributário). Assim, é necessária uma lei de caráter administrativo (CARRAZZA, 2006, p. 504) que determine a prestação de serviço público, ou mesmo o exercício do poder de polícia, e outra de caráter 
tributário que determina que uma vez realizadas tais atividades, será gerada a taxa pelo exercício do poder de polícia. Em todos estes casos, há produção de norma abstrata e geral.

O poder de polícia em sentido amplo é inerente a toda pessoa pública, no Brasil, cada qual na forma e limites constitucionais de sua competência. Não é o exercício do poder de polícia neste sentido amplo que autoriza a cobrança de taxa, porque não se poderia conceber, como sua hipótese de incidência o exercício - pelo poder público - das faculdades ínsitas no poder de polícia (ATALIBA, 1969, p. 47). Somente o autoriza o poder de polícia que se consubstancia num agir concreto e específico da Administração, praticado com base em lei e que levanta uma abstenção ou que mantém ou fiscaliza uma exceção já existente.

Trata-se aqui do poder de polícia em sentido estrito, que é a fiscalização do Estado para o cumprimento das restrições, contidas em leis, ao uso pleno da propriedade privada e ao exercício da liberdade individual plena. Esta fiscalização se concretiza na produção de normas concretas e individuais também contidas em atos administrativos. Paga-se taxa de polícia quem ocasiona as despesas ao Poder público em promover essa fiscalização que são atos de vistorias, perícias, verificações, avaliações, cálculos, estimativas, entre outros que condicionam atos de autorizar, licenciar, homologar, negar, denegar, proibir etc. A emissão de um juízo expressivo do poder de polícia é precedido de diligências fiscalizatórias para instrução e informação de modo a se condicionar o ato culminante final de um procedimento administrativo, $\mathrm{o}$ ato de polícia. O poder polícia abrangeria esses três momentos: a lei, o regulamento e o ato administrativo fiscalizador e concretizador dos dois primeiros.

Inúmeros exemplos pertinentes à matéria podem ser apontados, um deles é o que tange à lei de zoneamento, uma "lei administrativa", que determina restrições ao uso pleno da propriedade, fixando zonas residenciais, industriais, áreas de expansão urbana. Para se exercer uma atividade comercial, deve-se obter uma licença (norma concreta e individual) contida num alvará, instrumento de consubstanciação do exercício do poder de polícia, que implica uma exceção, manutenção ou fiscalização, que somente é concedido pelo Poder Público após este fiscalizar o cumprimento das restrições ao uso da propriedade. A taxa é devida em decorrência das despesas do Poder Público com esta fiscalização.

Outro exemplo seria acerca dos Municípios, que têm competência de polícia e estabelecem leis sobre segurança, higiene, saúde, etc, aplicáveis a estabelecimentos que 
"recebem" o público. Para observar a segurança de tais normas, cada Município condiciona o funcionamento desses estabelecimentos a licenciamentos prévios. A lei confere a uma autoridade municipal a função de conceder tal licença, desde que as leis tenham sido cumpridas. A autoridade para conceder a licença ordena, de acordo com a lei, que funcionários vistoriem os estabelecimentos para informar se suas condições de funcionamento estão de acordo com as exigências legais, informando o processo, relatando o que fizeram e o que apuraram. De acordo com estas informações, a autorizada nega ou concede a licença solicitada.

O poder de polícia aqui exposto qualifica-se como "regular", este adjetivo conforma-o como poder de polícia hábil à instituição de taxas de polícia, e diz respeito aos limites da competência administrativa da autoridade que pretenda exercê-lo, à capacidade de agir em relação a determinada atividade, de acordo com as garantias do contraditório e ampla defesa por parte daqueles cujos direitos, interesses e atividades sejam limitados por meio deste policiamento. Não só a legalidade do procedimento característico do exercício do poder de polícia deve ser considerada, mas também a moralidade e a finalidade do ato administrativo de que resultará a atividade polícia, nos limites legais da discricionariedade administrativa, sempre analisada tendo em vista a motivação do ato administrativo. Assim dispõe o Código Tributário Nacional:

Art. 78, CTN. [...]

Parágrafo Único. Considera-se regular o exercício do poder de polícia quando desempenhado pelo órgão competente nos limites da lei aplicável, com observância do processo legal e, tratando-se de atividade que a lei tenha como discricionária, sem abuso ou desvio de poder.

Esse contexto pode ser verificado concretamente na hipótese em que alguns municípios, após concederem alvarás iniciais para prática de atividades e após ter cobrado respectiva taxa, passaram a exigir nova taxa sob o pretexto da renovação anual da referida localização, sem que um novo zoneamento tivesse ocorrido, ou se alterado a situação fática. A renovação da licença para exercício de certa atividade é permitido, desde haja novos fatos que justifiquem a reiteração anual da licença já anteriormente concedida. 


\subsubsection{Taxa de polícia e necessidade de efetiva atuação estatal}

A maioria da doutrina ainda considera necessária haver efetiva fiscalização (efetiva atuação estatal) para se caracterizar o exercício do poder de polícia e assim o critério material da hipótese da taxa de polícia. Ainda é minoria a parte da doutrina que seria possível cobrar taxa de polícia daqueles que potencialmente usufruirão a estrutura administrativa estabelecida para a fiscalização por parte do Poder Público, não havendo efetivo exercício do poder de polícia. "A demonstração de que a justificação e assento das taxas está nas diligências condicionadoras do ato e não no próprio ato está em que, sendo este positivo ou negativo, cabe a taxa" (ATALIBA, 1970, p. 485). A taxa de polícia não remunera o ato de polícia em si, que não contêm qualquer caráter econômico, mas sim as diligências e procedimentos que a Administração Pública realizou para exercer o poder de polícia, assim, mesmo que indeferido o primeiro, o interessado não se eximirá do pagamento da taxa pertinente. A taxa deve ser paga por ocasião do ato, mas com fundamento nas diligências que o precederam.

Nem a anterior Constituição e nem a atual fazem referência à regularidade do exercício do poder de polícia como pressuposto para a cobrança de taxas, o que entendo mesmo desnecessário, pois considero que a atividade está implícita na própria natureza do poder de polícia e no pressuposto da legalidade dos atos administrativos (MIRANDA DE CARVALHO, 1999, p. 161).

Para a maioria da doutrina a cobrança baseada no custeio da estrutura inerte da Administração é uma cobrança característica de impostos, pois custearia serviços gerais e a própria estrutura administrativa, o que caracteriza o regime jurídico próprio dos impostos, e deve ser realizado segundo as condições econômicas de cada indivíduo e na proporção da contraprestação ao cidadão contribuinte específico.

A adoção de uma definição constitucional de taxa, o que a faz rígida, teve como objetivo obstar abusos e evitar a prática de se criarem impostos sob a figura de taxas. "É certo que a nossa Constituição não define as taxas, mas também é certo que nela estão todos os elementos (aspectos) necessários à sua perfeita conceituação jurídica" (MIRANDA DE CARVALHO, 1999, p. 115). A ocorrência deste fenômeno traz sérias conseqüências para o sistema tributário brasileiro: os administradores, notadamente do Executivo Municipal, buscando aumentar a arrecadação dos cofres públicos que administram, tentam "driblar" a 
estrita previsão constitucional de critérios materiais das hipóteses de incidência dos impostos municipais, estaduais e federais, que não podem ser alteradas infraconstitucionalmente.

Esta fixação da Constituição implica uma boa definição da competência de cada ente federado, evitando a invasão da competência de um por outro. Os Municípios, então, se valem das taxas, principalmente daquelas decorrentes do exercício do poder de polícia e utilizam como critérios materiais de suas hipóteses, critérios materiais já utilizados em hipóteses de impostos estaduais ou federais ou ainda não previstos como tais, mas impossível de sê-lo em decorrência da exaustão por parte da Constituição Federal, sempre justificando que tais critérios caracterizariam o exercício do poder de polícia por parte da Administração. "O Estado não pode manipular os procedimentos próprios do poder de polícia, nem as diligências por eles exigidas, nem os órgãos ou atos pelos quais se veicula seu exercício, para incrementar suas receitas" (ATALIBA, 1970, p. 490).

Exemplifica-se esse equívoco com a situação da "taxa de alvará" ainda cobrada em muitos municípios, apesar de considerada inconstitucional porque cobrada a "renovação da autorização" para o exercício de atividades econômicas, principalmente comerciais. $\mathrm{Na}$ verdade, esta cobrança, que geralmente era anual, era uma cobrança por renovação de licença, não existindo fiscalização ou efetivo exercício do poder de polícia, já que a licença é concedida uma única vez. O cidadão quando instala suas atividades econômicas é licenciado e não autorizado, não existindo renovação de licença. Esta "taxa de alvará" não se confunde com a taxa de verificação de funcionamento regular, decorrente da necessidade de o Poder Público fiscalizar o exercício regular das atividades licenciadas, taxa constitucional e legal.

Outro exemplo pode ser observado no Código Tributário Municipal de São Paulo, que prevê em seus Arts. 126 e 185 duas taxas:

Art. 126. A taxa de licença para localização e funcionamento de estabelecimentos [...] fundada no poder de polícia do Município, quanto ao zoneamento da cidade e ao ordenamento das atividades urbanas, tem como fato gerador o licenciamento obrigatório daqueles, bem como a sua fiscalização quanto às posturas edilícias $e$ administrativas constantes de legislação municipal, relativas à higiene, segurança, moralidade e sossego público (grifos nossos).

Art. 185. Fundada no exercício de polícia do município, a taxa de serviços diversos tem como fato gerador a utilização obrigatória de serviços especiais visando à observância de normas concernentes à segurança, higiene e saúde públicas (grifos nossos). 
No caso do Art. 126, apesar de um texto que sugere sistematicamente duas hipóteses tributárias de taxa de polícia, tem-se que se trata de uma única hipótese já que o licenciamento somente consubstanciará o exercício do poder de polícia constante de atos de fiscalização.

Já, no caso do Art. 185, há uma incongruência ainda mais grave: intitula uma taxa decorrente do exercício do poder de polícia de taxa decorrente da prestação de serviço público, fazendo entender que os "serviços" a que se refere são aqueles enumerados (e não conceituados) pela Constituição Federal e explicitados pelo Art. 79, CTN. Na verdade, estes "serviços" são atividades de vistoria de prédios, instalações etc.

É imprescindível para a caracterização do efetivo exercício do poder de polícia a edição de "lei administrativa" e "lei tributária". Por força do princípio da legalidade, o poder de polícia, num primeiro momento, deve ser exercitado por meio de uma lei editada por pessoa política que tiver competência administrativa para limitar a liberdade e a propriedade das pessoas, fixando inicialmente em nível genérico e abstrato a limitação e se seguindo a produção de regulamentos, que dão plena eficácia às leis e atos administrativos que fiscalizam e compelem os particulares à observância desses preceitos legais.

\section{Conclusão}

A matéria tributária é sempre motivo de divergências doutrinárias, em função de seu caráter eminentemente patrimonial, atingindo diretamente os interesses dos cidadãos, indiscriminadamente. Discussão aqui levantada tomou afeto ao tributo taxa, em especial ao critério material de sua hipótese de incidência: exercício do poder de polícia.

A relação jurídica tributária é deflagrada no momento em que o evento tributário (fato concreto) subsume-se à hipótese tributária, constante da norma jurídica tributária. Nesse momento cria-se o fato jurídico tributário, que deflagrará a relação jurídica tributária, e assim será instaurada a obrigação tributária. A discussão que se trava na doutrina está na própria hipótese tributária, especificamente em seu critério material.

A doutrina majoritária entende que para caracterizar o critério material da hipótese tributária, e assim ser possível deflagrar a relação jurídica tributária, é necessária a efetiva atuação estatal. Para outra parte da doutrina, a mera potencialidade dessa atuação já seria suficiente para a subsunção do evento à hipótese tributária. 
Para a corrente dominante, a cobrança do tributo aqui exposto seria meio de custear a atividade estatal despendida direta, ou indiretamente, a um sujeito determinado. Ou seja, para arcar com as despesas com a efetiva movimentação da máquina estatal para a fiscalização de um sujeito, e sua atividade específica, cabendo apenas a tal ônus.

Diante da principiologia apontada ao longo do texto, sendo um dos fundamentos do Estado brasileiro a igualdade, quer seja em seu aspecto formal, ou material, e a conseqüente isonomia, o único entendimento cabível é aquele que direciona o ônus da prestação estatal a seu "beneficiado", assim, deve ser efetiva sua atuação.

Caso entendesse que caracterizaria o critério material da hipótese pela mera potencialidade da atuação estatal, estar-se-ia realizando cobrança em função da estrutura administrativa inerte, o que seria uma cobrança característica de impostos, custeando serviços gerais.

O que se tem em vista é a atuação específica, individual e efetiva do Estado, com o fim de fiscalizar a adequação dos particulares à disciplina limitadora dos direitos à propriedade e à liberdade.

\section{Referências}

ATALIBA, Geraldo. Considerações em torno da Teoria Jurídica da Taxa. Revista de Direito Público, São Paulo, v. 9, n. 9, p. 43-54, jul./set. 1969.

. Taxa pelo Exercício do Poder de Polícia - Fato Gerador - Base de Cálculo. Revista de Direito Administrativo, Rio de Janeiro, n. 102, p. 474-95, out./dez. 1970.

BANDEIRA DE MELLO, Celso Antônio. Curso de Direito Administrativo. 17. ed. São Paulo: Malheiros, 2004.

BARRETO, Aires F.; BARRETO, Paulo Ayres. Imunidades Tributárias: limitações constitucionais ao Poder de Tributar. São Paulo: Dialética, 2001.

BUSSAMARA, Walter Alexandre. Taxas. Limites Constitucionais. São Paulo: Malheiros, 2002.

CARRAZZA, Roque Antônio. Curso de Direito Constitucional Tributário. 22. ed. São Paulo: Malheiros, 2006.

CARVALHO. Paulo de Barros. Curso de Direito Tributário. 16. ed. São Paulo: Saraiva, 2004. 
. Direito Tributário: Fundamentos Jurídicos da Inciência. 3. ed. São Paulo: Saraiva, 2004.

MACHADO, Hugo de Brito. Curso de Direito Tributário. 23. ed. São Paulo: Malheiros, 2004.

MIRANDA DE CARVALHO, Rubens. Contribuição de Melhoria e Taxas no Direito Brasileiro. São Paulo: Juarez de Oliveira, 1999.

PAULSEN, Leandro. Direito Tributário. Constituição e Código Tributário à Luz da Doutrina e Jurisprudência. 4. ed. São Paulo: Livraria do Advogado, 2002.

PEREIRA FILHO, Luiz Avlberto. As Taxas e os Preços no Ordenamento Jurídico Brasileiro. In DINIZ DE SANTI, Eurico Marcos (Coord.) Curso de Especialização em Direito Tributário: estudos em homenagem a Paulo de Barros Carvalho. Rio de Janeiro: Forense, 2005.

SOUZA, Rubens Gomes de. Sujeito Passivo das Taxas. Responsabilidade por transferência e substituição. Revista de Direito Público, São Paulo, v. 16, ano IV, abr./jun. 1971.

VIEIRA, Eugênio Doin. Taxas - Algumas Considerações Propedêuticas. In BANDEIRA DE MELLO, Celso Antônio (Org.). Estudos em Homenagem a Geraldo Ataliba. Direito Tributário. São Paulo: Malheiros, 2001. 